\title{
2006-864: ENGINEERING EFFECTIVE MIDDLE SCHOOL TEACHER PROFESSIONAL DEVELOPMENT
}

\section{David Burghardt, Hofstra University}

Dr. M. David Burghardt is Professor, Chair of the Engineering Department, and co-Director of the Center for Technological Literacy at Hofstra University. He is the author of 11 engineering and technology education texts, numerous publications, and is Principal Investigator of the NSF MSP grant, Mathematics, Science and Technology Education Partnership.

\section{Maryann Llewellyn, Uniondale School District}

Dr. Maryann Llewellyn is Deputy Superintendent of the Uniondale School District and oversees the curriculum and instruction in the district. 


\title{
Engineering Effective Middle School Teacher Professional Development
}

\begin{abstract}
The Math Science Technology Education Partnership (MSTP, 2003) is one of the NSF MSP targeted projects that has as its primary mission the improvement of middle school mathematics instruction and student learning in mathematics, science, and technology education classes. It is the only MSP project that uses engineering design as one of its key elements. The thesis of the project was simple: with more instructional time devoted to mathematics, and with mathematics taught with current pedagogical practice, student learning should improve. The MST Professional Development Academy grew out of this effort.

Most often professional development involves teachers attending classes to learn new content and pedagogy. Since the experience, however engaging, is disconnected from teachers' classroom experience, new practices are hard to implement in the classes. The MST Summer Professional Development Academy, created with 55 sixth and seventh grade students and 14 middle school math, science and technology education teachers, addresses traditional professional development deficiencies. Uniondale School District, a participating school district in the project, wanted teachers to implement a comprehensive, interdisciplinary quarterly project for students that coincided with the end of marking periods.
\end{abstract}

Engineering design was used in the creation of multi-disciplinary projects and strategies for assessing student learning were used as teams of students were completing their design projects.

The paper will explain the summer academy; discuss the teacher reaction to the professional development; and analyze teacher perception of student learning. The data collected by the MSTP project's evaluator as well as information gleaned from teacher journals and teacher observation data will be used.

\section{Introduction}

The Uniondale School District on Long Island faces the challenges of many other high-needs districts, with many families living at or below the poverty level, yet the district is deeply committed to improving teaching and learning of middle school mathematics. To help meet this challenge, the district agreed to participate with a local university in a National Science Foundation targeted Math Science Partnership grant called the Mathematics, Science and Technology Education Partnership (MSTP).

Uniondale was one of ten districts participating in the project. The school population in Uniondale is $66 \%$ African-American and 31\% Hispanic; $42 \%$ of the students are eligible for free lunch.

An important feature of MSTP is that each school district could shape how it provided professional development and how it built a MSTP community. The first year was spent in developing a leadership team for the school, a team composed of mathematics, science, and 
technology education teachers, a guidance counselor, an administrator, and two university STEM faculty. STEM is NSF shorthand for Science, Technology, Engineering, and Mathematics. In Uniondale, the STEM faculty come from mathematics and engineering. In the second year the team ran awareness workshops and, with district help, recruited teachers for summer professional development.

\section{Research}

There is a belief among MSTP professionals that the solutions to problems lie within the organizations and need to be discovered and nurtured. This is in contrast to externally imposed remedies, which often have short-term success but not the sustainability of organic solutions. Barbara Waugh (2001) discusses the organic organizational model she and others created in regard to her experiences at Hewlett-Packard. Jerry Sternin (Sparks, 2004) has refined the concept of "positive deviance" to help communities alleviate malnutrition, businesses to become more productive and schools to improve student learning. The phrase, "positive deviant", is initially a bit off-putting, but it refers to that person within an organization or group who is outperforming the average, using the same resources as everyone else.

This organic institutional model is entirely consistent with the MSTP project; at the outset the project goal was not to impose solutions, but to provide resources to help districts create solutions that would work in their environments. Inherent in the organic institutional model, and necessary for searching for and implementing the results of positive deviants, are the requirements of intellectual and emotional commitment by the stakeholders. For MSTP this includes teachers, students, administrators, parents, and community leaders.

When the traditional school year in Uniondale ended in June after students have completed the state required 185 days of classes, summer sessions began for high-achieving students and those requiring remediation. However, there were no provisions to support the average student. With NSF funding, we searched for ways to create an innovative and effective summer professional development experience for teachers, one that would be sustainable after the NSF project was completed. Most often professional development involves attending classes to learn new content and pedagogy. Since the experience, however engaging, is disconnected from teachers' classroom experience, new practices are hard to implement in the classes (Martin-Kniep, 2004). The MST Summer Academy was created with 55 sixth and seventh grade students and 14 middle school math, science and technology education teachers.

\section{MST Summer Academy}

We also sought to break down disciplinary barriers between STEM teachers so communication and mutual understandings could develop. As part of its strategic planning, Uniondale wanted teachers to implement a comprehensive quarterly project for students that coincided with the end of marking periods. With MSTP the project became interdisciplinary and offered teachers the opportunity to create more engaging challenges for students. This enabled them to develop and use complex projects where they could teach for meaning and understanding (McTighe, Seif, Wiggins, 2004). 
During the school year it is difficult to create and critique a unit, because teachers always need to push ahead to the next topic. This summer experience changed that dynamic. The teachers were placed on grade-level STEM teams with colleagues from their school (there are two middle schools in Uniondale). Once the multidisciplinary project was conceived, it would be taught and revised several times, allowing teachers to focus on what worked, what did not. Thus they could make changes and re-teach the activity.

As part of the MSTP project, we had researched student performance data and found that percent, measurement, area, and perimeter were concepts students did not demonstrate understanding of on standardized examinations. In part the difficulty arose from instruction too frequently occurring at too low a level. For instance, in asking math teachers how they taught percents, most gave formulaic answers that failed to teach depth of understanding. When discussing area, the approach was the memorization of an equation with a mnemonic.

In this three-and-one-half week professional development experience, the first week was spent in introducing teachers to current middle-school mathematics content and pedagogy. The goal in the beginning of the week was to have all teachers re-learn math concepts that are major obstacles to students in an engaging process.

In the next two and one-half weeks, teacher teams would teach the unit four times in two threeand-a-half hour sessions. This modeled eight to nine class periods during the school year. However, since the unit was being team taught, the actual time in the school year would be half that, as support and design activities would coordinately occur in science, math, and technology education classrooms.

Exemplary Materials

Using the methodology from exemplary NSF materials, teachers were engaged in measuring the areas and perimeters of different shapes and computing the areas. Mathematics teachers were introduced to new pedagogical approaches. Science and technology education teachers were provided with ways to assist students in applying their mathematical knowledge to understand a science concept or create a technological design. Following two days of intense mathematics enhancement, the teachers applied mathematical reasoning in science and technology education. They performed several science experiments in which mathematics was essential to the understanding and completion of the activity.

\section{Math Infusion}

Math infusion in science is one of the features of the MSTP project. Enhanced infusion occurs when students need to apply math, such as in a lab where they need to graph and interpret data or make measurements. Dependent infusion occurs when a topic is introduced where mathematical reasoning is essential to understanding the science. For example, the use of Punnett squares in genetics.

Informed Design 
Engineering design, in particular the informed design process (Burghardt \& Hacker, 2004) (NYSCATE, 2003), was used in the creation of multi-disciplinary projects. The classroom application of design has teams working to create solutions to a problem for which there is no correct answer, but only a correct process. Hence creativity is encouraged; there is no one solution. Students find this very engaging, as do teachers.

In design projects, there is a challenge with specifications and constraints. The specifications indicate what the design must accomplish, and typically the constraints are limitations in terms of materials and time. Teachers, working in their school and grade-level teams, spent a day designing and constructing model emergency shelters for different biomes that had to satisfy the specifications in terms of scale, protection from animals or insects, and the weather. The specifications required an understanding of science, and mathematics to be met, but the team's particular solution was open-ended.

A key idea in the informed design process is to have scaffolding math, science and technology activities that "inform" student knowledge before the design is attempted. These activities are called knowledge and skill builders (KSBs). The process is very consistent with the "backwards design" process advocated by Wiggins and McTighe (2005).

After this experience, the teacher teams were given the challenge of designing their own multidisciplinary projects that could be implemented in the first or second marking period. The projects were created to reinforce key ideas in science and math that were covered in the marking period and that aligned with the state standards. There was sharing of information about the designs with one another to obtain feedback and improve design solutions. This is a pedagogical feature of informed design. Teachers developed their initial lesson plans to implement with the MST Academy students.

\section{Academy Experience}

The students arrived on Monday morning and went to their first three-and-a-half hour class. During this time the KSBs were taught in the context of the design challenge. The second day was spent on constructing, testing, and evaluating the design. Teachers spent the two afternoons revising the instructional materials. The cycle repeated itself on the third day with students attending a different two-day session.

As Richard DuFour (2004) points out, there are three important factors in professional learning communities, with the first factor, and perhaps the foremost, ensuring that students learn. There was a great deal of focus on what the major concepts were, how teachers could determine if students learned them, and what pedagogical strategies they could employ to improve student understanding. The repetition of the unit allowed the teachers to hone these skills.

One teacher's comments, echoed by others was "The ability to spend time revising and reflecting on our curriculum as a team was great" (Teacher Journal, 2005). The advantage of trying out materials in a low-risk environment and being able to refine them again and again cannot be over-estimated. During this time, the grade-level teacher teams bonded. They also began sharing ideas for the forthcoming academic year. The school administration made a 
commitment that the teachers would have the same cohort of students, possibly including the students who attended the summer academy, plus common prep time and often back-to-back scheduling of STEM classes, so occasional double periods will be possible.

After two cycles of teaching the activity, the teachers were becoming comfortable with their design challenges, refocusing the KSBs, and guiding the students. However, they and we had learning expectations for the students. How could these be assessed? In a summer MST academy, giving tests and quizzes was not viewed as appropriate. However, honoring teachers' classroom knowledge and ability to assess student knowledge through questioning was appropriate. While one might think this is easy to implement as teachers agreed they do constantly assess student understanding, it was not initially embraced.

\section{Bloom's Taxonomy}

Following a discussion of the questioning the teachers did with the students, they were asked what they knew about student understanding of the math and science concepts. This led to a discussion of Bloom's taxonomy (1956) and how we might employ it to assess student learning at different levels. While the formal taxonomy has six different levels, the teachers decided that being able to distinguish three levels while engaged in the classroom was the maximum they could perceive - knowledge, comprehension, and application/analysis (KCA).

The afternoons revolved around discussion of these levels and what they meant. Just as the workshop provided time for the teachers to try and re-try the interdisciplinary project, it also provided time for trying and re-trying teacher perception of student learning. Since there were on average three teachers for 12-14 students, there was sufficient opportunity for assessment of all the students.

The teachers developed guiding questions at the basic, middle, and upper levels of understanding (KCAs) in content areas of mathematics and science. The student responses were typically assessed on a Likert scale for each question. A student might demonstrate a four at the knowledge level, but a one at the application/analysis level. The teachers gained insight into student learning, "I learned how to give informal assessment in a more direct way" (Teacher Journal 2005). Tables 1 and 2 indicate questions that were asked at the three levels in science and mathematics, respectively, developed by one teacher. Figures 1 and 2 indicate the student responses. This teacher used a 5 point Likert scale, where 1 indicated that the student did not know anything about the question, 3 indicated the student needed prompting by the teacher to answer the question, and 5 indicated that the student could answer correctly with teacher prompts.

Table 1 Science Topic-Working with Biomes

\begin{tabular}{|l|}
\hline Knowledge Level-Verbalizations/language used by students-Define \\
biome and adaptation. \\
\hline $\begin{array}{l}\text { Comprehension-Appropriate use of language/terms by students-What } \\
\text { type of climate, plant life, and animals are found in your chosen biome? }\end{array}$ \\
\hline $\begin{array}{l}\text { Application - demonstrate understanding through design, drawing, essay, or } \\
\text { solution of a word problem-How is your animal adapted to your biome (e.g. } \\
\text { food procurement, body covering, teeth, eye placement)? }\end{array}$ \\
\hline
\end{tabular}




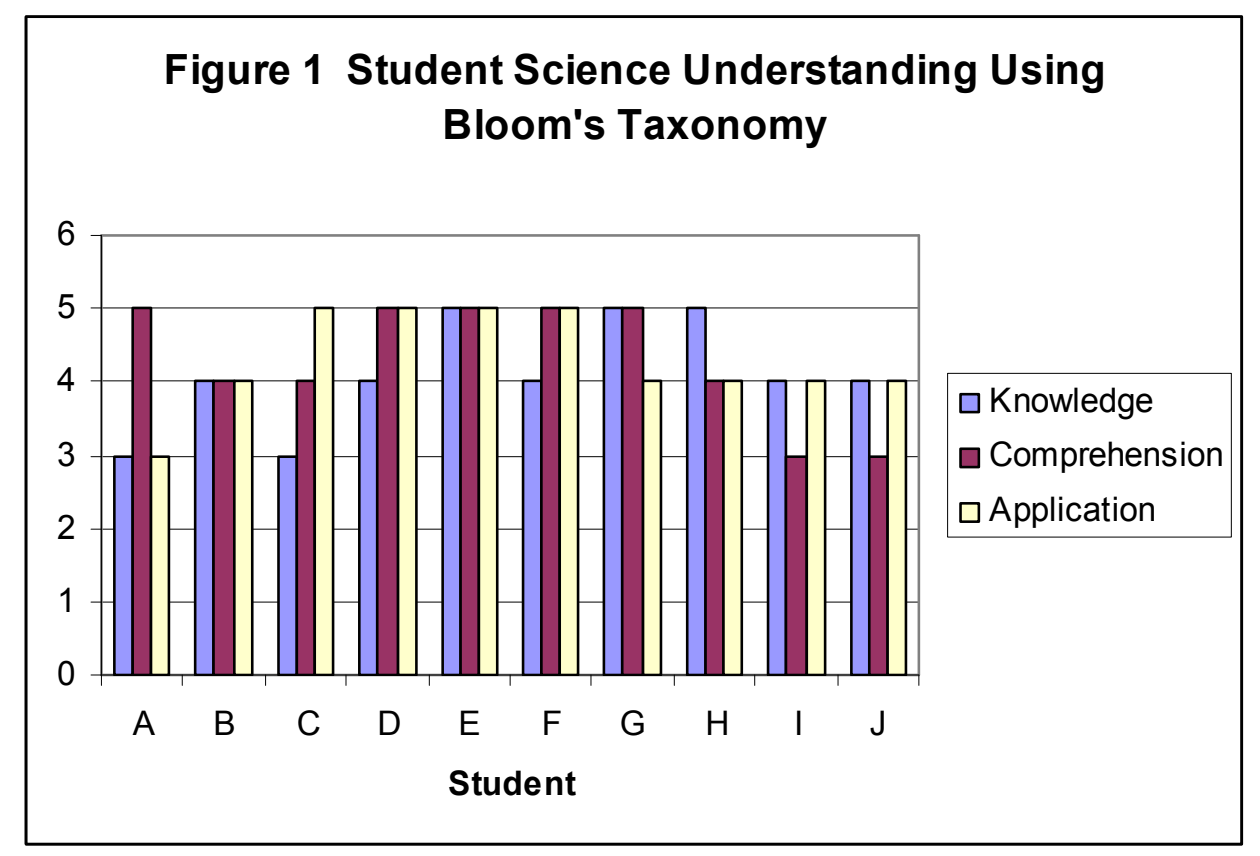

Table 2 Math Topic-Working with Scale

Knowledge Level-Verbalizations/language used by students-Define scale. Comprehension-Appropriate use of language/terms by students - Why was the use of scale necessary for this project?

Application - demonstrate understanding through design, drawing, essay, or solution of a word problem-Describe the steps used to compute scale? 


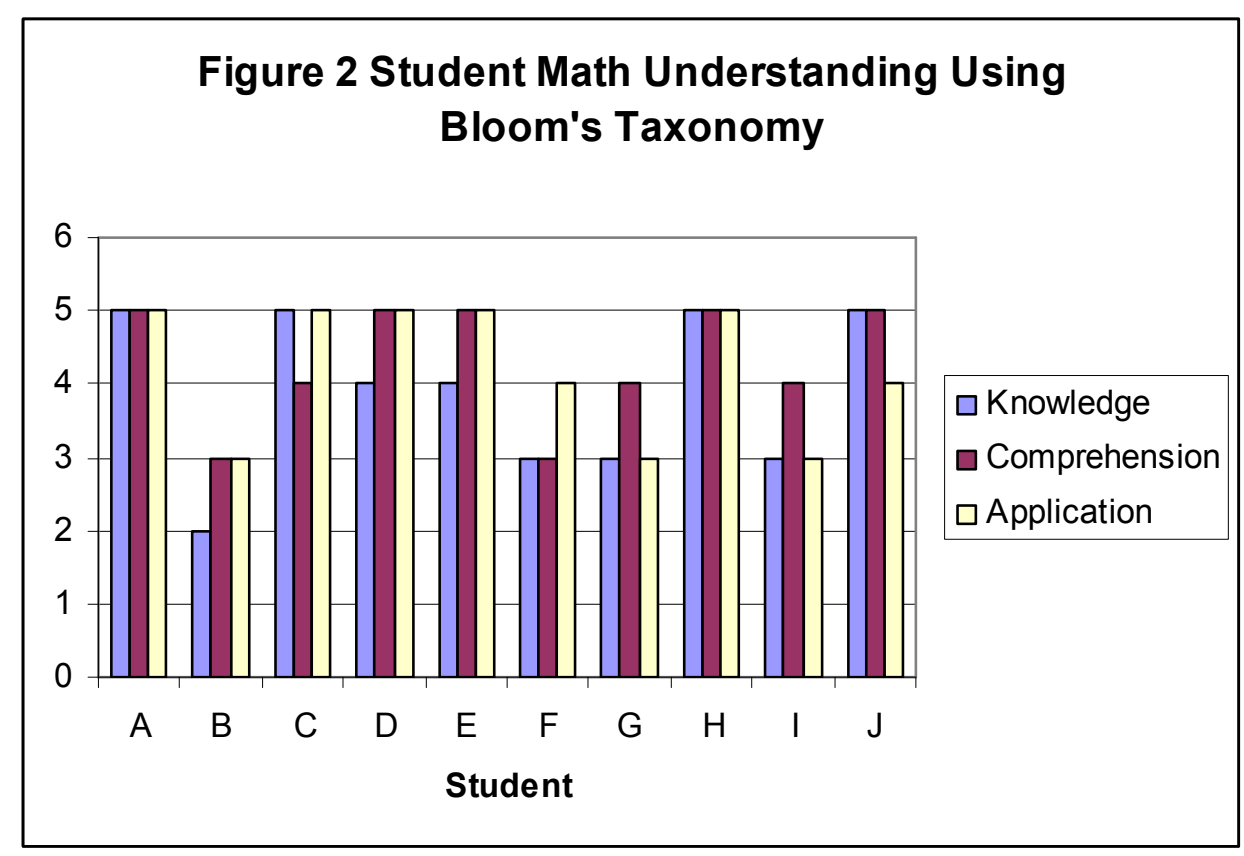

The afternoon workshops also provided teachers with methodologies for analyzing the data. The MSTP project had hosted the first Long Island Show-Me Conference (2005) in conjunction with the NSF Show-Me Center (2005). This was a regional conference that highlighted exemplary middle school mathematics materials and STEM instructional practices. Many of the teachers had attended. We planned a Show-Me Exhibit, so students could display their work and teacher teams could indicate what learning had occurred, hence the need for data regarding student learning.

\section{Show-Me Exhibit}

Depending on one's point of view, the Show-Me Exhibit became the carrot (or the stick) for teachers to display and describe student learning. Parents, the superintendent and staff, school administrators, and local politicians were all invited, and attended. The teacher teams realized that what they perceived about student learning mattered and had to concretized and displayed in informative ways. Their perceptions of student knowledge related to the key ideas were displayed in graphical forms. Administrators queried the teachers, as did parents, and were very pleased at the depth of knowledge the teachers had gained about content, pedagogy, teaming and, most importantly student learning. The attendees were also impressed by student teams presenting what they had done and what they had learned.

The teachers found that the workshop to be very beneficial. As Figure 3 (based on responses from Table 3) illustrates the ratings were consistently high, except teachers wanted more time to implement units with children. They believed that six hours was not sufficient time. However, students liked the pace and the two-day rotation cycle. 
Table 3 Overall workshop rating

\begin{tabular}{|l|l|}
\hline & $\begin{array}{c}\text { Poor--------- } \rightarrow \text { Excellent } \\
\text { (1) }\end{array}$ \\
\hline Information presented & \\
\hline Materials provided & \\
\hline $\begin{array}{l}\text { Amount of time for } \\
\text { activities }\end{array}$ & \\
\hline Opportunities for Q\&A & \\
\hline $\begin{array}{l}\text { Opportunities to learn } \\
\text { from others }\end{array}$ & \\
\hline $\begin{array}{l}\text { Relevance for your } \\
\text { classroom }\end{array}$ & \\
\hline $\begin{array}{l}\text { Information about } \\
\text { enhancing mathematics }\end{array}$ & \\
\hline $\begin{array}{l}\text { Information about } \\
\text { infusing math into } \\
\text { science and technology }\end{array}$ & \\
\hline
\end{tabular}

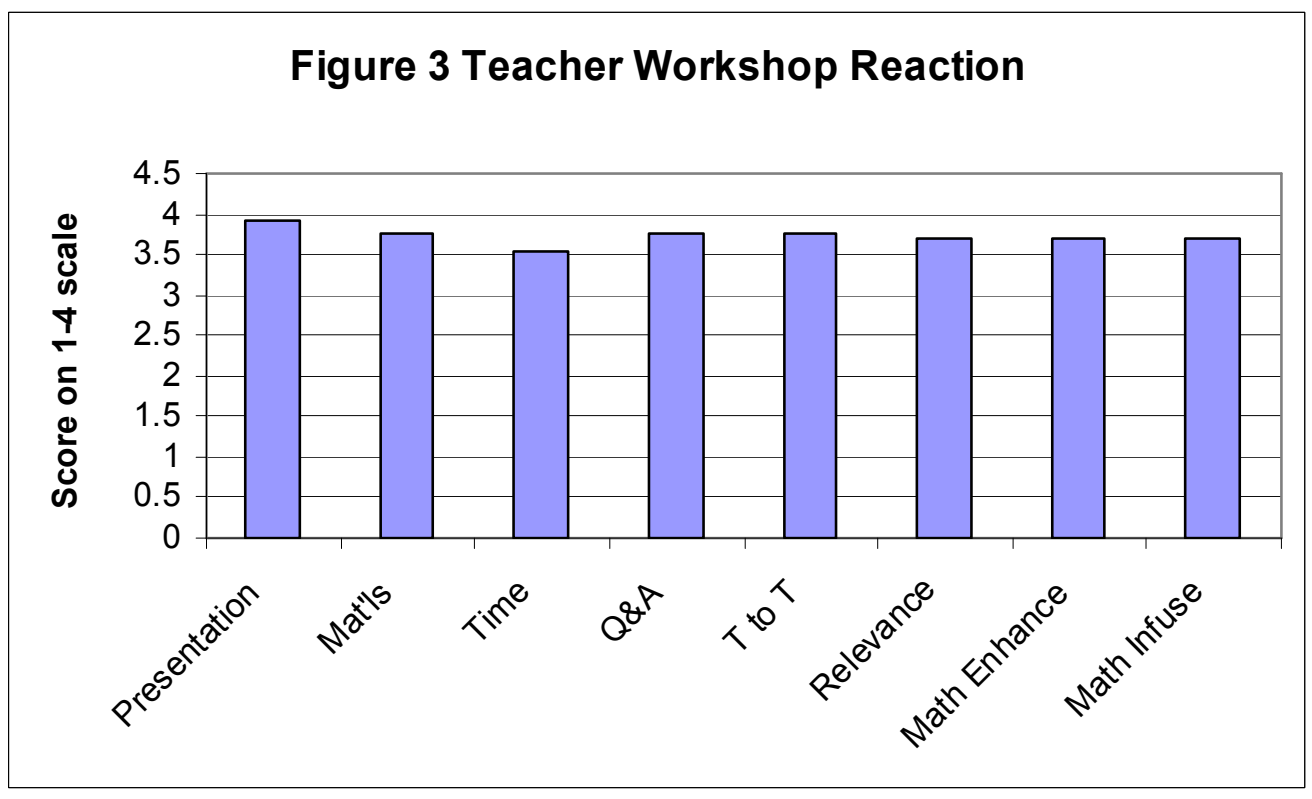

As Figure 4 (based on responses from Table 4) illustrates, teachers found that the workshop was very beneficial, with the exception of not being quite certain what they would be expected to do as a result of the workshop during the academic year. This was addressed in follow-up meetings at the start of the academic year. 
Table 4 How well do you understand:

\begin{tabular}{|l|c|}
\hline & $\begin{array}{c}\text { Not at all------- } \rightarrow \text { Completely } \\
\text { (1) }\end{array}$ \\
\hline $\begin{array}{l}\text { What you will be doing as a part } \\
\text { of the MSTP team }\end{array}$ & \\
\hline $\begin{array}{l}\text { How this project will help you } \\
\text { meet the needs of your students }\end{array}$ & \\
\hline $\begin{array}{l}\text { What the curriculum is trying to } \\
\text { teach }\end{array}$ & \\
\hline $\begin{array}{l}\text { How to integrate math into science } \\
\text { and technology }\end{array}$ & \\
\hline $\begin{array}{l}\text { The role of the faculty team } \\
\text { members }\end{array}$ & \\
\hline $\begin{array}{l}\text { How to use this information in } \\
\text { your classroom }\end{array}$ & \\
\hline $\begin{array}{l}\text { What will be expected of you next } \\
\text { year }\end{array}$ & \\
\hline
\end{tabular}

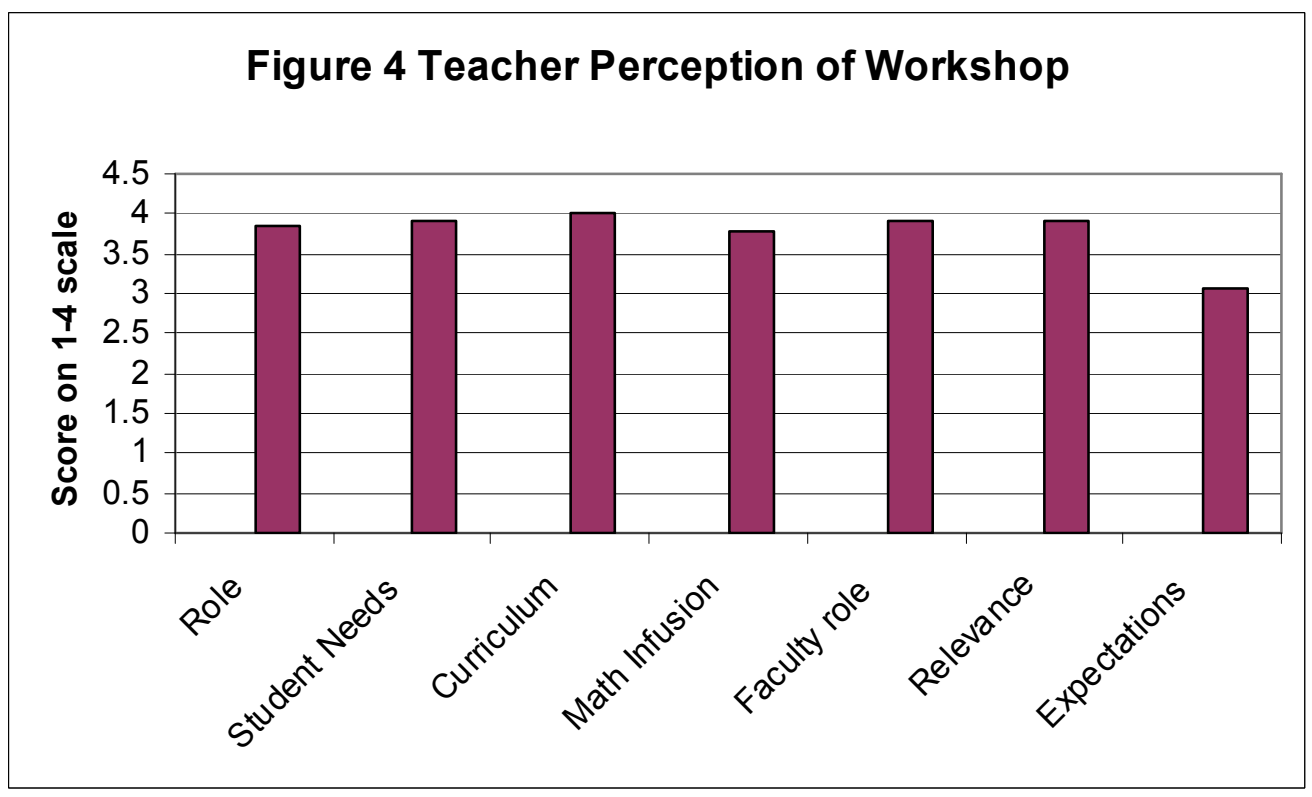

Teachers also provided written comments about the workshop and what they valued most. There were two themes from that appeared most often; one, the ability to work with ones and refine the activities; and two, that the students could present what they learned at the Show-Me Exhibit. We had anticipated that many teachers would like and benefit from teaching and reteaching the same unit with colleagues. This has continued into the academic year as interdisciplinary relationships developed over the summer have maintained themselves with teachers seeking one another's advice re math, science and technology issues. What was more 
surprising was the second finding that including a finale where students would present what they learned to their parents, community leaders and school administrators was quite important. We will plan to include this element in future MST Academy workshops. This is particularly important as teachers also present their perceptions of student achievement, so they liked the challenge of presentations for themselves and for their students.

\section{Conclusion}

As the school year begins, the teachers will be provided with ongoing support to build on the work of the summer. The bonds that were created will be strengthened by having common planning time and the same student cohorts. All the teachers said they want to attend next summer's professional development program, and there is a commitment from the district to expand the summer academy as a model for professional development. The intellectual and emotional involvement is growing, and teachers are learning from one another within and across disciplines.

\section{Acknowledgment}

The authors would like to acknowledge the support provided by the National Science Foundation through Award \# EHR 0314910.

\section{References}

Bloom Benjamin S. (editor) (1956). Taxonomy of Educational Objectives-The Classification of Educational Goals. Handbook I. The Cognitive Domain. New York, Longman.

Burghardt, M.D \& Hacker, Michael. (2004). Informed Design: A Contemporary Approach to Design Pedagogy as the Core Process in Technology, Technology Teacher. 64,1.

DuFour, Richard. (2004). What is a "Professional Learning Community"?. Educational Leadership. 61, 8.

Martin-Kniep, Giselle O. (2004) Developing Learning Communities through Teacher Expertise. Corwin Press. Thousand Oaks, CA.

McTighe, Jay, Seif, Elliott, Wiggins, Grant. (2004). You Can Teach for Meaning. Educational Leadership. $62,1$.

MSTP Project. (2003). Retrieved from http://hofstra.edu/MSTP August 13, 2005.

MSTP Show-Me Conference. (2005). Retrieved from http://hofstra.edu/Academics/SOEAHS/TEC/tec_mstp_showMe_curriculum_showcase_and_conference.cfm August $13,2005$.

NYSCATE. (2003). New York State Curriculum for Advanced Technological Education. Retrieved from www.hofstra.edu/nyscate August 9, 2005.

Show-Me Center. (2005). Retrieved from http://www.showmecenter.missouri.edu/showme/center.htm. August 13, 2005 . 
Sparks, Dennis. (2004). Positive Deviance Approach seeks solutions that already exist. Journal of Staff Development. 25, 1 .

Waugh, Barbara. (2001). Soul in the Computer. Inner Ocean Publishing, Maui, HI.

Wiggins, Grant \& McTighe, Jay. (2005). Understanding by Design, expanded $2^{\text {nd }}$ edition. ASCD. Alexandria, Va. 